\title{
Study of the Weight of Eggs from Six Ixodid Species from Brazil
}

\section{Marcelo Bahia Labruna ${ }^{+}$, Romário Cerqueira Leite, Paulo Roberto de Oliveira}

Departamento de Medicina Veterinária Preventiva, Escola de Veterinária, Universidade Federal de Minas Gerais, Caixa Postal 567, 31270-901 Belo Horizonte, MG, Brasil

Eggs from engorged females of six ixodidae species (Ixodes loricatus, Amblyomma rotundatum, A. cajennense, Haemaphysalis leporis-palustris, Boophilus microplus, Dermacentor nitens) maintained in laboratory were counted to calculate the number and mean weight in $1 \mathrm{~g}$ of eggs from each species. Phylogenetic considerations are discussed based on the results.

Key words: Ixodidae - Amblyomma - Ixodes - Haemaphysalis - Dermacentor - Boophilus - Phylogeny - Brazil

The generally large acarines included in the superfamily Ixodoidea apparently evolved as obligate parasites of Reptilia in the late Paleozoic or early Mezozoic era. During subsequent coevolution with birds and mammals, adaptations of most tick species have been conservative. Structural, developmental, physiological, ethological, and reproductive properties and processes have changed, but chiefly within narrow parameters (Hoogstraal \& Kim 1985).

In Brazil, there are 54 known tick species (Aragão \& Fonseca 1961). Among the Ixodidae, the genus Ixodes (Prostriata, Ixodinae) is represented by 9 species. In the Metastriate line, Amblyomma (subfamily Amblyomminae) is the largest genus constituted by 33 species. The Haemaphysalinae (genus Haemaphysalis) is represented by only 3 species. The remaining species belong to the Rhipicephalinae. Boophilus microplus was introduced in Brazil with cattle by Portuguese in the XVI century. Rhipicephalus sanguineus has spread out among the world parasitizing dogs, Canis familiaris, which are not the host they coevolved with. Another species, Dermacentor nitens, possibly penetrated in South America during Pliocene with the massive invasion of North America mammals across the newly formed isthmus of Panama (Balashov 1994). Among the Argasidae, the genus Argas (Argasinae) is represented by A. miniatus, endemic in Latin America. The genus Ornithodoros (Ornithodorinae) contains 6 species parasitizing mainly bats, although they often feed on humans and other

${ }^{+}$Corresponding author. Fax: +55-31-441.9918

Received 24 June 1996

Accepted 25 November 1996 mammals. The subfamily Otobinae is represented in Brazil by the species Otobius megnini.

The mean number of eggs in $1 \mathrm{~g}$ of eggs is not known for the majority of these species. There are few reports on egg weights for tick species in the literature. Reports from other countries have noticed the following values (eggs/g): B. microplus: 20,408.16 (Lahile 1917 cited by Alvarado \& Gonzales 1979), 20,000.00 (Drummond et al. 1973), 22,727.27 (Quevedo 1966 cited by Alvarado \& Gonzales 1979) D. nitens: 15,625.00 (Dunn 1915). From Brazil, there are reports on eggs/g: $H$. leporis-palustris: 14,285.71 (Rhor 1909), A. cajennense: 16,400.00 (Prata et al. 1995a), B. microplus: 19,685.03 (Alvarado \& Gonzales 1979), D. nitens: $17,100.76$ (Prata et al. 1995b). In this work, the amount of eggs in $1 \mathrm{~g}$ of eggs was comparatively studied for 6 ixodid species from Brazil, the results were related to the possible origin and evolution of ticks.

\section{MATERIALS AND METHODS}

To determine the whole egg output of at least 4 engorged females for 6 ixodid species, the females were collected from naturally infested animals in the Southeast region of Brazil, as follows: Ixodes loricatus (Ixodinae) on marsupials Didelphis albiventris from Belo Horizonte, State of Minas Gerais (MG). Haemaphysalis leporis-palustris (Haemaphysalinae) on rabbits Sylvilagus brasiliensis from Caratinga, MG. Two Amblyominae, A. rotundatum on toads Bufo sp. in Belo Horizonte and A. cajennense collected on horses from Pedro Leopoldo, MG. The Riphicephalinae B. microplus and D. nitens respectively on cattle and horses from Pedro Leopoldo. All ticks were identified according to specific taxonomic keys (Robinson 1926, Cooley 1946, Aragão $\&$ Fonseca 1961, Price 1969).

All engorged females were taken into a BOD 
cabinet at $27 \pm 1{ }^{\circ} \mathrm{C}$ and at least $85 \%$ relative humidity $(\mathrm{RH})$. As soon as they completed the egg output, 10 samples of 100 eggs from the egg pool of each species were counted and weighted in a $0.001 \mathrm{~g}$ precision electronic balance. The values were reported and the mean value for each species was calculated. The number of eggs in $1 \mathrm{~g}$ of eggs was calculated dividing 100 by the respective mean value. The mean reproductive efficiency value (RE) with the respective standard deviation (SD) was calculated for $12 \mathrm{~A}$. rotundatum females and 13 A. cajennense females, according to the formula:

$$
\mathrm{RE}=\frac{\text { weight of total egg output }}{\text { weight of engorged female }} \times 100
$$

\section{RESULTS}

The mean weight and respective SD values for 10 samples of 100 eggs for each species and the calculated number of eggs in $1 \mathrm{~g}$ of eggs are shown in the Table. Twelve A. rotundatum females showed a mean $\mathrm{RE}$ value of $53.9(\mathrm{SD}=4.34)$ and 13 A. cajennense females showed a mean RE value of $57.9(\mathrm{SD}=5.7)$.

\section{DISCUSSION}

It can be seen that there are large variations of number of eggs for different genera and species (A. cajennense and A. rotundatum). The values now found also show differences with other studies concerning the same species. It suggests natural differences between tick strains, since they are from disctint geographical areas, however some of these differences might be due to the size variability of eggs laid by the same female. Oliver (1989) and Prata et al. (1995a) reported that eggs' size do not remain constant during the oviposition, varying during the course of oviposition period. The egg mass differences reported in the literature for one species is generally slight, supporting some of the differences now observed between different species.
The genera Amblyomma and Ixodes are cosmopolitan. Species of Ixodes are distributed in all climatic zones while Amblyomma spp. only in the tropics and subtropics. Evidently, the ancestors of these genera existed before the break up of Pangea in northern (Laurasia) and southern (Gondwana) halves (Balashov 1994). This event is dated to the middle of jurassic (Queen 1983 cited by Balashov 1994). Ticks evolved as obligate parasites of Reptilia in the Paleozoic or early Mezosoic era (Hoogstraal \& Kim 1985), or else during the Devonian period, as admitted by Oliver (1989), considering the acarine radiations and the development of a great variety of amphibians that could be hosts to ticks. In that time, tick eggs were of greater size and consequently were laid in less amount per female. Primitive bird and mammal lines greatly diversified, evolved into numerous specialized orders, and replaced reptiles as the dominant land vertebrates in the early Tertiary. Adaptative radiation of ticks also occurred at this time, and ticks coevolved with their hosts (Oliver 1989).

According to Table, $1 \mathrm{~g}$ of eggs of $A$. rotundatum has a much smaller amount of eggs than the other ticks which seems to be a primitive character that this tick seems to retain since it coevolved with amphibians and reptilia. $A$. cajennense shows a greater number of eggs/g since this species coevolved with mammals and birds. $I$. loricatus also shows a much lower number of eggs when compared with Rhipicephalinae. It is in agreement with Pomerantsev (1948) cited by Balashov (1994), whose hypothesis is that the first hosts of primitive ixodid were monotremes and marsupial, and to which the most primitive subgenera of the genus Ixodes are presently associated. According to Hoogstraal and Kim (1985), in the 155 species of the genus Haemaphysalis, 17 are structurally primitive species, 4 are structurally intermediate and the remainder are structurally advanced. H. leporis-palustris is cathegorized as a structurally advanced species (subgenera Gonixodes) which agrees with the high number of

\section{TABLE}

Mean weight and standard deviation for 10 samples of 100 eggs from 6 females ixodid species, and number of eggs in $1 \mathrm{~g}$

\begin{tabular}{lccc}
\hline Ixodid species & $\begin{array}{c}\text { Mean weight of } 10 \\
\text { samples of 100 eggs }(\mathrm{g})\end{array}$ & Standard deviation & $\begin{array}{c}\text { No. eggs in } \\
\text { 1g of eggs }\end{array}$ \\
\hline Ixodes loricatus & 0.0080 & 0.00000 & $12,500.00$ \\
Amblyomma rotundatum & 0.0115 & 0.00053 & $08,695.65$ \\
Amblyomma cajennense & 0.0053 & 0.00053 & $18,867.92$ \\
Haemaphysalis leporis-palustris & 0.0060 & 0.00000 & $16,666.66$ \\
Dermacentor nitens & 0.0055 & 0.00000 & $18,181.81$ \\
Boophilus microplus & 0.0050 & 0.00000 & $20,000.00$ \\
\hline
\end{tabular}


eggs/g found for this species in this study. Brumpt, in Nuttal and Warbuton (1915) cited by Hoogstraal and Kim (1985), reports some structurally primitive species such as H.(A.) inermis and H.(A.) kitaokai whose females deposit less than $25 \%$ of the total egg production of most other Haemaphysalis spp., which are structurally advanced. According to Balashov (1994), Dermacentor originated earlier than the Cretacous or Paleocene, and the genus Boophilus is recent and originated probably in Pliocene. These facts may justify the high number of eggs/g found for $D$. nitens and $B$. microplus in this and other studies. The observed $\mathrm{RE}$ values for $A$. rotundatum and A. cajennense females are similar to most ixodid females fed on their natural hosts and show that the reproductive efficiency is probably not correlated to egg size and consequently, to the amount of egg output.

\section{ACKNOWLEDGEMENTS}

To Prof. João LH Faccini and Prof. Pedro M Linardi for their suggestions.

\section{REFERENCES}

Alvarado RU, Gonzales JC 1979. A postura e viabilidade do Boophilus microplus (Canestrini, 1887) (Acarina, Ixodidae) em condições de laboratório. Rev Lat-amer Microbiol 21: 31-36.

Aragão H, Fonseca F 1961. Notas de Ixodologia. VIII. Lista e chave para os representantes da fauna ixodológica brasileira. Mem Inst Oswaldo Cruz 59: 115-129.

Balashov YS 1994. Importance of continental drift in the distribution and evolution of ixodid ticks.
Entomol Review 73: 42-50.

Cooley RA 1946. The genera Boophilus, Rhipicephalus and Haemaphysalis (Ixodidae) of the New World. National Institute of Health, Washington D.C., 54 pp.

Drummond RO, Ernest SE, Trevino JL, Gladney WJ, Graham OH 1973. Boophilus microplus and $B$. annulatus. Laboratory tests of insecticides. J Econ Entomol 66: 130-133.

Dunn LH 1915. Observations on the preoviposition and incubation periods of Dermacentor nitens in Panama (Arach., Acar.). Entomol News 26: 214-219.

Hoogstraal H, Kim KC 1985. Tick and mammal coevolution, with emphasis on Haemaphysalis, p. 505-568. In KC Kim, Coevolution of parasitic arthropods and mammals. John Wiley \& Sons, New York.

Oliver Jr JH 1989. Biology and systematics of ticks (Acari: Ixodida). Annu Rev Ecol Syst 20: 397-430.

Prata MCA, Deamon E, Sanavria A 1995a. Determinação de ovos por grama de postura de Amblyomma cajennense (Fabricius, 1787) (Acari: Ixodidae). Rev Bras Parasitol Vet 4 (Supl.1): 64.

Prata MCA, Morais MC, Sanavria A 1995b. Determinação de alguns parâmetros de Anocentor nitens (Neumann, 1897) (Acari: Ixodidae) em infestação artificial de equinos. Rev Bras Parasit Vet 4 (Supl.1): 50.

Price MA 1969. Keys for the determinations of ticks and mites of medical importance. College Station, Texas, $25 \mathrm{pp}$.

Robinson LE 1926. Ticks: A monograph of the Ixodoidea IV: The Genus Amblyomma. Cambridge University Press, London, 302 pp.

Rohr CJ 1909. Estudos sobre Ixódidas do Brasil. Instituto Oswaldo Cruz, Rio de Janeiro, 220 pp. 
